\title{
LETRAGRAFÍA
}

\section{Síntesis y comunicación visual}

\author{
Lettergraphy. Synthesis and Visual Communication
}

SANTIAGo OSNAYA BALTIERRA

Universidad Autónoma del Estado de México, México

\section{KEY WORDS}

Alphabet

Letters

Typography

Visual Communication

Characters

Signs

\section{ABSTRACT}

Letters appeared in the world as a necessity for communication. They were created as images which represented ideas and sounds. Through time letters were transformed into what people now know as an alphabet. Today this language system seems to be invisible, probably because of the everyday with which it is manipulated. In this sense the objective of the text is to propose a semantic distancing from the conventional use of letters to state that through the form and expressiveness of each letter it is possible to transmit a message.

\section{PALABRAS CLAVE}

Alfabeto

Letra

Tipografía

Grafía

Caracteres

Signo

\section{RESUMEN}

Las letras aparecieron en el mundo como una necesidad de comunicación. En sus inicios, éstas fueron creadas como imágenes que representaban ideas y sonidos, a través del tiempo se convirtieron en lo que se conoce como alfabeto. Hoy en día dicho sistema de lenguaje parece ser invisible debido a la cotidianeidad con que es manipulado. El objetivo del texto es proponer un distanciamiento semántico del uso convencional que tienen las grafías que conforman el abecedario, para plantear que a través de la forma y expresividad de cada letra es posible transmitir un mensaje.

Recibido: 09/09/2019

Aceptado: 06/11/2019 


\section{Introducción}

$\mathrm{E}$ s imposible conversar en torno al término letra sin hacer una breve mención del desarrollo histórico de la misma. Roger Chartier (1994, p. 5) explica que toda transformación relacionada con la comunicación hace necesaria una reflexión histórica del fenómeno en cuestión, ya que ningún acontecimiento se da de forma espontánea. Por ello, en los párrafos subsecuentes se ofrece a manera de introducción un breve panorama del origen de la escritura.

En la barbarie ${ }^{1}$ los primeros grupos sociales eran familiares, ellos obtenían su conocimiento de la naturaleza; de ahí que las primeras formas de escritura ${ }^{2}$ fuesen pictogramas, los cuales eran representaciones de la naturaleza como la luna, el sol, los animales, etcétera. A este respecto, Carlos Marx (Marx y Hobsbawn, 1971, p. 14-16) dice que el hombre crea y reproduce su existencia en la práctica diaria al respirar, buscar alimento, cobijo, amor... Todo esto lo llevan a efecto actuando en la naturaleza, tomando de ella lo necesario para poder cubrir sus necesidades fisiológicas y afectivas. De tal forma que la mayoría (si no es que todos) de los objetos que el ser humano produce son resultado de la interacción entre hombre y naturaleza. Cada objeto es similar en mayor o menor medida al contexto en el cual fue creado, por ello es posible decir que la naturaleza es parámetro indispensable para cualquier diseño; por ejemplo, el tenedor y la cuchara guardan estrecha similitud con las manos del hombre. De ahí que en sus orígenes los primeros signos escritos tengan gran similitud con el entorno de aquellas primeras civilizaciones. A este respecto se puede citar el caso de la letra "A", la cual proviene, en primera instancia, de la representación de una cabeza de buey (Ver imagen 1).

\footnotetext{
${ }^{1}$ Es la primera forma de propiedad comunitaria; se presenta como primer presupuesto una comunidad natural. Ellos se relacionan con la tierra ingenuamente como con la propiedad de la comunidad, y de la comunidad que se produce y se reproduce mediante el trabajo vivo. Cada individuo se relaciona sólo como miembro de esta comunidad, como propietario o poseedor. Véase Marx y Hobsbawn, 1971, pp. 84-85

2 Los primeros vestigios de la escritura son del año $3300 \mathrm{AC}$ en Mesopotamia en la región de Uruk, Susa, Ur, Jemdet Nasr.
}

Imagen 1. Proceso evolutivo de la letra "A"
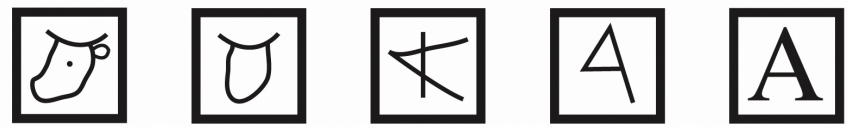

Fuente: adaptado por el autor del sitio, www.rsub.com/typographi

La primera forma económica capitalista denominada barbarie fue la que dio origen a la escritura. En aquella época esta invención no se utiliza como medio para representar su lengua, sino que se recurría a ella para fines contables, es decir, su uso era para llevar un registro administrativo y económico. Los primeros vestigios encontrados en Mesopotamia de la escritura sumeria ${ }^{3}$ son muescas, puntos, rayas, nudos, colores que significaban cantidades, tipos de cosas contadas o registros de información de las cosas. Este tipo de sistemas gráficos de numeración fueron una manera de acuñar la memoria.

En los inicios de la humanidad, los mensajes orales tenían dos severas limitaciones: el espacio y el tiempo. Este medio de comunicación solamente podía recorrer una pequeña distancia antes de deshacerse, ya que las vibraciones del aire generadas fonéticamente sólo eran audibles durante fracciones de segundo. Apenas el hablante había cerrado su boca, ya no quedaba nada de su mensaje. De ahí que la escritura sea la primera técnica artificial inventada para superar esa doble limitación del habla, la espacial y la temporal (Mosterín, 1993, p.160).

El modo de existencia de aquellas civilizaciones primitivas fue la tribu. Su característica primordial era la falta de permanencia en un lujar fijo ${ }^{4}$; este tipo de comunidades se tornan itinerantes debido a la constante búsqueda del alimento. A medida que éste se va extinguiendo, el grupo se desplaza para encontrarlo en otro lugar (Marx y Hobsbawn, 1971, p. 15). Por ello, no es coincidencia que la región conocida como Mesopotamia haya sido un territorio importante

\footnotetext{
3 A los sumerios se les acredita un gran número de inventos, como el uso de ladrillos en sus edificaciones, la rueda, el torno de cerámica y un sistema numérico. Véase Martínez, 1990, pp. 11

${ }^{4}$ A esta actividad de desplazamiento se le da el nombre de nomadismo. El diccionario de la Real Academia Española dice que nómada es aquella persona que vive errante, sin domicilio.
} 
en donde se gestaron las primeras civilizaciones, pues dicha zona era una tierra fértil y próspera para obtener y producir productos alimenticios. Ello debido a su cercanía con los ríos Tigris y Éufrates, los cuales garantizaban la existencia de los grupos familiares que vivían de la pesca, la recolección o la cacería.

El constante desplazamiento ${ }^{5}$ de estos grupos permitió el contacto e interacción con otras familias facilitando la transmisión del conocimiento, propiciando con ello la modificación y transformación de los signos escritos. En otras ocasiones, la relación entre las tribus no se daba en una situación pacífica sino por conflictos territoriales. En esos casos, la cultura se imponía o adoptaba por parte de conquistadores o vencidos respectivamente.

Cuando existe una acumulación de conocimientos naturales el hombre pasa de ser nómada a sedentario. 6 A esta formación económica se le conoce como comunitaria ${ }^{7}$ siendo sus principales actividades la agricultura, la domesticación y cría de animales, la alfarería, el tejido, entre otras. Dichos procesos de producción voluntaria pasaron del autoconsumo (satisfacer solamente las necesidades de la comunidad) a la producción del excedente, lo que llevó a dichas comunidades al intercambio ${ }^{8}$ o trueque de animales, frutos y utensilios. Este gran dinamismo comercial aumentó la necesidad de comunicación entre los individuos, lo que probablemente también propició la evolución del alfabeto occidental, el cual hoy en día es utilizado en casi todo el mundo. Friedrich Engels (Braverman,

\footnotetext{
${ }^{5}$ En la primera forma de propiedad de la tierra, aparece ante todo una entidad comunitaria resultante de un proceso natural, la familia devenida en tribu, donde el nomadismo constituye uno de los primeros modos de existencia. Ibíd.

${ }^{6}$ Los acadios son uno de los primeros pueblos que se vuelven sedentarios.

${ }^{7}$ Esta comunidad es el primer presupuesto de la apropiación de las condiciones objetivas de su vida, y de la reproducción y objetivación de la actividad de la que viven. La tierra es el gran laboratorio, el arsenal, que provee tanto el instrumento de trabajo, como el material del mismo, así como también provee el lugar que constituye la base de la comunidad. Marx y Hobsbawn, 1971, pp. 85

${ }^{8}$ El hombre, como animal social, desarrolla la cooperación y una división social del trabajo, lo cual no sólo posibilita la producción de un excedente sobre lo necesario para el mantenimiento del individuo y de la comunidad a la que pertenece, sino que, además, incrementa la posibilidad de esa producción excedentaria. La existencia de ese excedente, unido a la división social del trabajo, hacen posible, a su vez, el intercambio. Ibíd. pp. 15
}

1980, p. 65) expresó, "primero el trabajo, después de él y luego junto con él el lenguaje".

\section{Desarrollo}

El lenguaje escrito ha sido objeto de estudio de diversos investigadores como Jesús Mosterín, Marcel Cohen, Albertine Gaur, Gregorio Caja, Alfred Moorhouse, Sergio Pérez, Florian Coulman, entre otros. Debido a esto no es extraño encontrar una vasta literatura al respecto. Sin embargo, poca atención se le ha dado a aquellas unidades que hacen posible la transmisión, el acopio y la producción de las ideas. Es a ellas a las que el presente texto desea que se voltee la mirada, las cuales son comúnmente conocidas como letras y que han terminado por perderse en el océano de lo escrito, ya que, cuando hay que referirse a ellas, las denominamos "alfabeto", "abecedario", tipografía", etcétera. No hay que olvidar lo que menciona Emil Ruder, "El mundo de lo escrito comienza con la letra" (Ruder, 2002:12).

Si se toma como referencia la definición de la palabra letra, de acuerdo al Real Diccionario de la Lengua Española, encontraremos que ésta es definida como: "Cada uno de los signos o figuras con que se representan los sonidos de un alfabeto". En este sentido, se entiende que la letra no puede ser utilizada con otro uso que no sea el de construir palabras, como lo afirma el tipógrafo Frederic Goudy9: "La letra no tiene particular significado hasta que es empleada para formar parte de una palabra". Sin embargo, este escrito pretende mostrar que las letras pueden alejarse del convencionalismo para el que fueron hechas: el lenguaje escrito.

A lo largo del texto se utiliza con toda intencionalidad la palabra letra con el propósito de rescatar el término, ya que éste ha venido a ser cada vez más raro y menos utilizado en las artes gráficas. El vocablo que es más común escuchar es la palabra tipografía, la cual es relativamente una expresión reciente que cubre diferentes significados relacionados con las palabras y las letras (McLean, 2000:25). Así, las formas del alfabeto han quedado comprendidas

\footnotetext{
${ }^{9}$ Frederic W. Goudy (1865-1947) fue uno de los diseñadores tipográficos más productivos, escribió libros como: The Alphabet (1908), Elements of Lettering (1921), Typoligía (1940).
} 
dentro del concepto tipografía, vocablo que aún continúa vigente en el área de la comunicación. Contrario a ello, en los años setenta el diseñador Félix Beltrán acuñó la palabra letragrafía para resaltar el hecho de que la letra tiene expresión y por lo tanto un valor visual significativo. Beltrán realiza un estudio de las letras desligando a éstas del texto en general y enfocándose más en la particularidad de cada uno de los caracteres del alfabeto para enfatizar su punto de vista en el acto comunicativo de cada uno de los signos gráficos. Para Félix Beltrán "La letra es una forma cargable de múltiples significados" (1973:22). A lo largo de su trayectoria como profesional del diseño gráfico, este diseñador enfatiza en cada uno de sus diseños que la letra es un signo de gran eficacia para comunicar, como se muestra a continuación en las imágenes dos y tres:

Imagen 2. Logotipo Hotel la Habana, Cuba

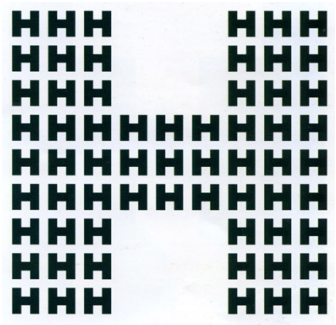

Fuente: Félix Beltrán, 1956.

Imagen 3. Logotipo Taxis Nacionales, Cuba.

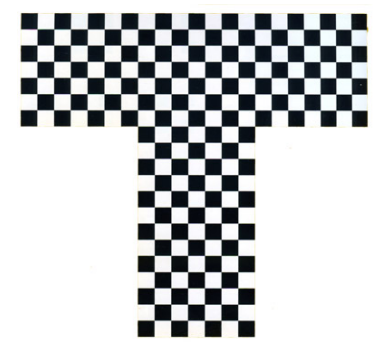

Fuente: Félix Beltrán, 1973.

Una referencia imprescindible para apoyar lo anterior es el semiólogo Roland Barthes, quien escribe: "Aunque la letra en apariencia resulta una imagen simple, ésta puede escapar en múltiples direcciones, una sola letra puede ser un símbolo que constituye un significante, un sintagma ajeno al sentido pero no al signo" (Barthes, 1986:104). Ejemplo de lo anterior (ver imagen 4 para el caso de la Ciudad de México, en México) puede ser la letra "E" (significante), que impresa dentro de una figura geometrica (círculo, cuadrado o rectángulo) colocado en un estacionamiento o vialidad adquiere la calidad de símbolo por ser una imagen convencionalizada en ciertas partes del mundo como México o Argentina, cuyo significado es "lugar para estacionarse" (Osnaya: 2019). Barthes (1986) sustenta su argumentación tomando como referencia a Robert Massin ${ }^{10}$, quien en su libro Letter \& Image (1970) expone ante los ojos del lector cada uno de los caracteres del alfabeto, con el fin de mostrar cómo a través de la forma de las letras se pueden generar discursos visuales. Massin demuestra a lo largo de su libro que la letra como imagen es capaz de transmitir una idea o un concepto; argumenta también que gráficamente ésta queda liberada de aquella función primordial que menciona Goudy. Massin rompe con el argumento en prosa utilizando una escritura no-fonética, la cual, de acuerdo a Jacques Derrida, es "Una escritura que describe relaciones y no denominaciones"(Derrida, 1971:35). Así, Massin utiliza las formas del abecedario como imágenes para generar una comunicación con el lector; un lenguaje silencioso que atrapa la vista del perceptor.

Imagen 4. Señal de estacionamiento permitido

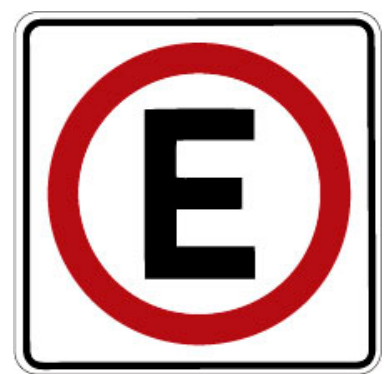

Fuente: adaptado por el autor, con base el Manual de Dispositivos para el control de tránsito en zonas urbanas u suburbanas de la CDMX (2001), México

Tal como se menciona en el párrafo anterior, pareciese que al haber un giro de sentido en el uso de la letra, se le tendría que desligar del sistema de comunicación para el que fue concebida; sin embargo, esto no tiene por que ser nesariamente así. Ya que en este contexto el uso de una sola letra como unidad de

\footnotetext{
10 Robert Massin es reconocido por su excelencia en el campo del diseño gráfico; ha sido director de arte, diseñador de libros, experimentador tipográfico, escritor, fotógrafo, músico...
} 
significación, implica también la factibilidad de catalogar está acción dentro de otra posible opción del lenguaje escrito. Pues dicho cambio de sentido puede entenderse como una manifestación del desarrollo de la escritura, es decir, un cambio que más que provocar una separación con el lenguaje escrito, exalta sus alcances presentes y futuros. Al respecto, Yuen Ren Chao en su texto Language and Symbolic Systems (lenguaje y sistemas simbólicos), menciona cuándo un símbolo puede o no ser considerado como escritura. Así, de acuerdo a Chao "Si el signo representa una parte específica del lenguaje, es escritura; si éste representa cosas directamente, no lo es" (Chao, 1970:101).

Por consiguiente, la letra-símbolo "M" colocada en las afueras de espacio arquitectónico o una vialidad para informar sobre un espacio recreativo es una expresión de la escritura, en tanto que no es la representación de una cosa sino la síntesis de la palabra "museo" (ver imagen 5). Lo anterior vendría a ser un claro ejemplo de las nuevas formas y aplicaciones del lenguaje escrito.

Imagen 5. Señal informativa de museo

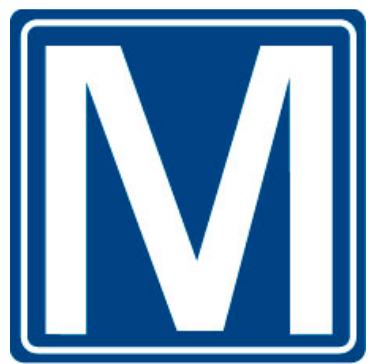

Fuente: adaptado por el autor, con base el Manual de Dispositivos para el control de tránsito en zonas urbanas o suburbanas de la CDMX (2001), México

De este modo, se sugiere que la letra no puede desligarse de la escritura en tanto que es muestra innegable de dicho sistema. En otras palabras: sin letras no habría escritura. Negar lo anterior sería tratar de borrar la historia de la misma. Con referencia a ello, Armando Petrucci argumenta que cada uno de los sistemas gráficos elaborados por los hombres tienen sobre su espalda una historia, signada por modificaciones, adaptaciones $\mathrm{y}$, a veces, auténticas revoluciones gráficas (2003:59). En el ejemplo siguiente (imagen 6) se muestra un ejercicio de diseño tipográfico que forma parte de un trabajo de investigación denominado "alfabeto visual", el cual fue desarrollado para coadyuvar de forma lúdica en la enseñanza de la lecto-escritura del idioma inglés en infantes de tres a cinco años de edad. La idea general del proyecto fue sintetizar diferentes palabras con una sola letra que representara concepto y significado. En el caso que aquí se expone, la palabra "travel" se comprime con la letra "T".

Imagen 6. Travel

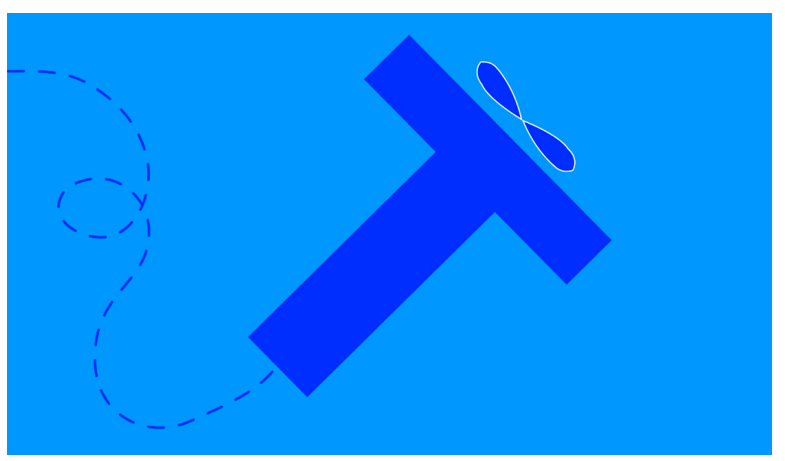

Fuente: Santiago Osnaya (2011).

La escritura no es simple repetición de lo oral, sino un medio material con nuevas necesidades y nuevas respuestas (Cortés, 1985:13). El lenguaje escrito ha sido pieza fundamental para grabar el pensamiento humano, convirtiendo algo efímero y volátil en concreto y permanente. De hecho, con el surgimiento del registro escrito, termina la prehistoria y comienza la historia de la humanidad. Alfred Moorhouse escribe: "El alfabeto es un método del lenguaje escrito que a diferencia de otros métodos de lenguaje, éste puede conservar su mensaje por un lapso de tiempo indefinido" (1961:15). Otra de las características importantes de este código escrito es la inminente abstracción del lenguaje oral. Basta decir que con la combinación de únicamente veintiséis caracteres el ser humano tiene la capacidad de transmitir cualquier pensamiento ya sea en área de la literatura, las ciencias, la historia y otras. La grafía alfabética es, en todo sentido, la simplificación de la lengua oral y escrita, bajo estas dos condiciones fue concebido el "alfabeto visual" anteriormente mencionado. Sin embargo, la cultura escrita no ha sido ni es la única muestra de síntesis en la historia de la humanidad. Dicho fenómeno de 
abstracción es igualmente observable en la pintura, el diseño, la música y la arquitectura.

En adelante, hablaremos de algunos ejemplos en los que la letra se ha tomado como elemento y síntesis de comunicación. La letra, como se ha visto, puede ser utilizada con otros fines distintos al de la conformación de palabras. El área de la comunicación es donde se observa una mayor cantidad de ejemplos y usos diversos, en los que se le da a la letra una jerarquía visual de gran importancia. Esto se debe, en cierta medida, a que los profesionistas tales como, tipógrafos, diseñadores, ilustradores y otros profesionales de este campo de trabajo conviven muy de cerca con la letras, lo que permite generar propuestas que dan un giro distinto al significado de éstas. Del lado contrario, las letras en el texto son como la desapercibida presencia de un segundo en lo inmensurable del tiempo. "Solamente con un esfuerzo de atención el inexperto descubre que ellas existen", escribe W. A. Dwiggins (Director de Publicidad).

Imagen 7. The action alphabet

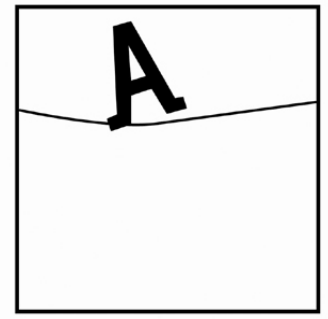

Fuente: Byron Glazer, 1992.

En la imagen 7 se observa que el mensaje que transmite esta imagen es realmente comprensible, lo que reafirma que las letras pueden ser utilizadas como medio para comunicar de manera clara y directa una idea. De la letra debemos diferenciar los dos ámbitos que la convierten en un ente complejo, su condición de signo representado, que se da como un objeto visual con todas las implicaciones que esto conlleva. Y su carácter simbólico que la hace un ente de significado, sentido e interpretación. La correlación entre estas dos condiciones de la letra hace un sofisticado juego de significaciónrepresentación que el diseñador debe conocer.
La letra se ve y se entiende, es forma e idea, es signo y símbolo (Esparza, 2003:1-7).

Acorde a lo anterior, si se toma una sola letra como elemento de comunicación visual, ésta tendría diversas posibilidades de uso, tal y como se ejemplifica en la imagen 7 , el poder convertirse en significante capaz de transmitir un mensaje se debe a que la letra tiene la cualidad de mirarse como forma e imagen y no únicamente como unidad para ensamblar palabras. "La letra", dice Roland Barthes, "es un símbolo que no se detiene por ser reversible, la letra I puede ser un reloj de arena, pero el reloj de arena puede llevarnos nuevamente a la letra I" (Barthes, 1986:119). No debe sorprender el hecho de que la letra tenga este doble sentido, pues dentro de la historia encontraremos que los orígenes del alfabeto occidental fueron ideogramas y pictogramas. Estos últimos eran representaciones de la naturaleza (la luna, el sol, los animales...), signos que guardaban gráficamente una semejanza con los objetos. Aquellos seres humanos realizaron un admirable proceso de análisis y abstracción del entorno (Moorhouse, 1961:26).

Si aquellas primeras grafías de la escritura tenían estrecha relación con las cosas, no es de extrañar, de acuerdo a Gamonal, que los caracteres alfabéticos puedan transmitir no sólo información textual, sino también múltiples emociones y sensaciones a través de su apariencia formal (Gamonal, 2005:5). Por ejemplo, en el campo de las artes visuales -y para ser más específicos, en la pintura- los movimientos artísticos como el futurismo, el dadaísmo, el conceptualismo, el constructivismo, la Bauhaus utilizaron como formas de expresión a las letras, incluso el graffiti lo hace actualmente, tal como se muestra en la imagen 8 .

Imagen 8. Tipografía \& Graffiti

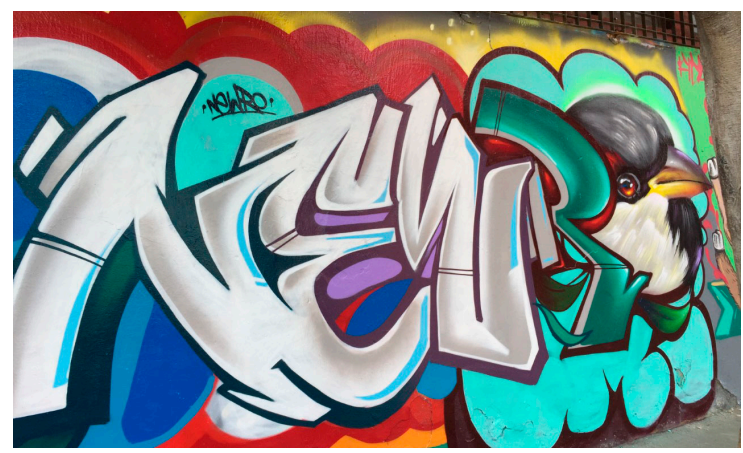

Fuente: César Itzcoatl Guerrero "Newro", 2019. 
En el ejemplo anterior (imagen 8) se utilizan los signos gráficos como elemento de comunicación, dejando ver el poder visual que tienen estos símbolos. Russell Bowman explica que en la pintura se emplean los signos verbales para engrandecer el potencial del significado (Bowman, 1985:335). Es relevante mencionar que, así como en las expresiones artísticas medios puramente visuales- se ha utilizado en cierta medida la grafía de la escritura como medio expresivo para manifestarse, la escritura también ha tenido que recurrir a los medios figurativos como la ilustración para cambiar su discurso de palabras por un discurso donde mayormente se haga uso de los dibujos. De esta forma fue que cierto número de palabras y consecuentemente enunciados o frases se sustituyeron a principios del siglo IX por una imagen que sintetizaba el mensaje escrito. Fue así como los escritores brindaron a los lectores algo para ver más que para leer, ellos comenzaron con ilustraciones para acompañar lo escrito y terminaron en algunos casos los libros de texto siendo libros de imágenes (Reid, 1994:5).

En el campo de la poesía también es posible encontrar casos en donde se mezcla la imagen y el texto con el objetivo de transmitir un mensaje más expresivo para el lector haciendo uso de los recursos visuales. Así, los poetas cargaron de significado el mensaje en dos sentidos: textual y visual. Escritores como Filippo Marinetti, Carlo Carrè, Ardengo Soffici, Stéphane Mallarmé, Guillaume Apollinaire, Arno Holz, entre muchos otros, son claro ejemplo de lo anterior, "ellos desafiaron la sintaxis, la gramática, el juego espacial de manera correcta" (Meggs, 2000:235).

Martine Reid y Nigel P. Turner (1994) en Legible/Visible, tratan el tema de la escritura y la imagen, respectivamente. En dicho texto los autores afirman que la barrera ilusoria entre lo legible y lo visible es borrada, ya que ambos campos guardan una estrecha relación el uno con el otro. A manera de analogía se puede mencionar el caso de la esteganográfica 11 utilizada en la Segunda Guerra mundial. Esta técnica sirvió para ocultar mensajes especiales y de un alto grado de confidencialidad, la cual

\footnotetext{
${ }^{11}$ La esteganográfica es el uso del legendario "microdot", que tiene que ver con la reducción de un escrito a las dimensiones de un punto, esto se hacía a través de un procedimiento fotográfico (Marrone, 2007:5-20).
}

consistía en la manipulación del significante (un signo tipográfico) para encubrir determinada información. Es decir, un punto o acento era visible, sin embargo, dicho elemento tipográfico, por un lado, representaba una imagen gráfica $y$, por el otro, significaba un texto secreto para ser leído. Jacques Derrida explica esta dicotomía (legible/visible) en términos de sensible (significante) e inteligible (significado). Para el filósofo estos dos elementos constitutivos del signo lingüístico se suponen y se requieren el uno del otro (1971:20).

Los románticos como Goethe y Schelling propusieron teóricamente el a sintetismo estético, el cual departía entorno a una unidad conformada por la unión de dos de contrarios que se complementaban el uno con el otro para emitir un mensaje. Es decir, para ellos un signo expresaba la representación perceptible de una idea, con rasgos asociados por un acuerdo socialmente aceptado. En este sentido, la idea del signo posee un vínculo convencional entre significante y significado; la generación de esta relación permite distinguir a un signo de otro. De ahí que el uso de las letras como pictografías puedan emitir y tener significado propio.

En el campo de las ciencias naturales y exactas esta dualidad del signo lingüístico es utilizada bastante bien. La química, las matemáticas, la física, llevan a estos signos al más elevado nivel de abstracción en cuanto a la inteligibilidad del signo, ya que su parte sensible es ya abstracta en sí misma. Para ejemplificar, pongamos el caso de $\pi$ como la parte sensible y 3.1416 como el lado inteligible; con ello se puede observar claramente cómo $\pi$ es la abstracción de seis caracteres tipográficos. Con el ejemplo anterior se demuestra que la utilización de números y letras sintetizan el lenguaje y facilitan a su vez la labor del científico. Es decir, partiendo de una serie básica de signos, el investigador crea en su cotidianeidad esquemas que le permiten formular de forma clara, ordenada y sintética los hechos, relaciones, problemas, predicciones, sucesos generales y particulares. Chao (1968) se refiere al lenguaje científico como una extensión del lenguaje natural, tomando en cuenta que éste es aquel que se desarrolló y creció de manera primaria como forma directa de comunicación entre la gente. 
Por esta razón, el lenguaje científico no nace directamente como grafía del lenguaje hablado, aunque sí utiliza los signos de la escritura, los cuales sí son la representación directa de los sonidos del lenguaje fonético (Chao, 1968:108).

\section{Conclusiones}

La escritura ha sido pieza fundamental en la construcción histórica de las sociedades y un instrumento esencial para dar cuenta de las realidades extintas y existentes; las personas se han servido de ella para manifestar y dar vida al pensamiento, al tiempo que ha sido manipulada, modelada y determinada por los factores políticos, económicos, sociales y culturales característicos de cada periodo histórico. Cada innovación es un acierto del ser humano en aras de mejorar, simplificar y engrandecer su existencia. Es por ello que el lenguaje escrito, que alguna vez surgió de la necesidad de comunicar cosas simples con signos complejos (aún en la actualidad los investigadores siguen tratando de descifrar dichos códigos escritos), ha llegado a través de un desarrollo de miles de años a comunicar la complejidad del pensamiento con signos abstractos y simples como las letras.

Parte de esa evolución histórica del alfabeto ha hecho que la letra, de acuerdo al uso que en ciertas circunstancias proporciona, pueda ser concebida como un sintagma (Barthes, 1986:104). Una letra-sintagma consigue leerse como un texto, una sola unidad puede contener un discurso, es decir, con una única letra se puede comunicar. Por ejemplo, la aplicación del signo "H" en un determinado lugar, es indicativo de que en ese sitio es posible hospedarse y descansar, así, la "H" es síntesis de la palabra hotel y de todos los servicios que este tipo de establecimiento puede ofrecer. La letra-sintagma reúne o contiene implícitamente una serie de palabras que el receptor, en la mayoría de las veces es capaz de eslabonar linealmente en su pensamiento para decodificar el significado del signo, $\mathbf{H}=$ Hotel=lugar de descanso. En palabras de Saussure, el sintagma se compone siempre de dos o más unidades significativas que están enlazadas entre sí una detrás de otra, dicha relación sintagmática se da in praesentia (Saussure, 2000: 173). El otro porcentaje de los receptores que no están en la mayoría antes mencionada, son aquellos que no cuentan con la instrucción para decodificar el signo lingüístico por no tener la capacitación para saber leer y/o escribir-. Por lo que éstos llevan a cabo la operación del significante-significado de manera indicial, es decir, ante un signo, marca o señal el individuo responde de forma operacional con una acción (como un indicativo de). En este caso, el signo adquiere significado por la experiencia de la persona y el convencionalismo de los signos. En este sentido, la señal "H" en casi todo el mundo refiere al establecimiento "hotel".

La letra es puro objeto de comunicación, información clara, da paso hacia lo inteligible y no sólo es expresión sensible. Lo que es propio del significante (la letra) es el hecho de constituir un punto de partida. El punto de partida del símbolo-letra es la letra misma. La letra simboliza, la forma es el contenido, el grafismo se basta a sí mismo, se desentiende de la palabra que vista desde esta perspectiva podría parecer frágil en un tiempo futuro. La letra comprime el lenguaje, no debe sorprender que una sola letra sea capaz de sintetizar una palabra, una idea o un concepto. Al liberarse de su papel lingüístico para conformar palabras, la letra puede llegar a decirlo todo. La letra al convertirse en un símbolo imagen puede ser interpretada universalmente.

El símbolo es la forma de exteriorizar un pensamiento o una idea. Aristóteles afirmaba que no se puede pensar sin imágenes. Se dice que el lenguaje simbólico es una manifestación evidente de la inteligencia; sin embargo, su utilidad curiosamente puede ser enfocada hacia grupos analfabetas y alfabetizados. En la sociedad tecnológicamente desarrollada, con la exigencia de comprensión inmediata, los signos del tipo símbolos son muy eficaces para producir una respuesta rápida en el perceptor o lector del signo. El símbolo se adscribe estrictamente primordialmente a elementos visuales por su simplicidad estructural, lo que proporciona facilidad de percepción y memoria. Un símbolo facilita la comprensión del lenguaje porque las personas no se ven en la necesidad de leer una palabra o un texto y, en el peor de los escenarios, ni siquiera tienen que saber que aquella letrasímbolo que están observando es una letra. Con el simple hecho de relacionar el símbolo con un 
significado es más que suficiente para que la persona pueda decodificar o entender un mundo en el que los mensajes son elaborados con simbolismos letragráficos.

Finalmente se puede decir que la importancia que han tenido las letras como código de comunicación en la vida de los seres humanos es indiscutible. Sin embargo, al convertirse la escritura en una parte fundamental de la vida de las personas, ésta termina por incrustarse de manera innata en la cotidianeidad de nuestra existencia, haciendo que las transformaciones o los cambios se tomen de forma natural. Por ello, esta investigación pretende fijar la atención en aquellas unidades (las letras) que por su uso habitual pasan casi desapercibidas para las personas. 


\section{Referencias}

Amin, S. (2003). Más allá del capitalismo senil. España: Paidós.

Attali, J. (1985). Historias del tiempo. México: Fondo de Cultura Económica.

Bairoch, P. (1990). De Jericó a México. Historia de la urbanización. México: Trillas.

Barthes, R. (1986). Lo obvio y lo obtuso. Imágenes, gestos y voces. España: Paidós.

Becerra, J. (1994). Tecnología del lenguaje. Revista estudios sobre las culturas contemporáneas, V(015).

Bloch, R. (1962). Orígenes de Roma. España: Argos.

Bowman, R. (1985). Words and Images: A Persistent Paradox. Art Journal, 45(4), pp. 335-343.

Braverman, H. (1980). Trabajo y capital monopolista. México: Editorial Nuestro Tiempo.

Bringman, G. The Semantics of Letter forms: Linguistic Variation and its Operative Artifacts http://www.litsciarts.org/slsa07/slsa07-91.pdf 10/11/2010

Carter, R., Day, B. and Meggs, P. (2002). Typographic design: form and communication. New York: John Wiley \& Sons, Inc.

Chartier, R. (1994). Del códice a la pantalla: las trayectorias del texto. Libros de México, 37, pp. 5-16.

Childers, T. (2002). All dressed up with something to say: effects of typeface semantic associations on brand perceptions and consumer memory. Journal of consumer psychology, 12(2), pp. 93-106.

Cundy, D. (1981). Marinetti and Italian Futurist Typography. Art Journal, 41(4), pp. 349-352.

Deibert, R. (1996). Typographica: The Medium and the Medievel-to-Modern Transformation. Review of International Studies, 22(1), pp. 29-56.

Doney, J. (2003). True to type. Graphics International, 104, 38.

Drucker, J. (1984). Letterpress Language: Typography as a Medium for the Visual Representation of Language. Leonardo, 17(1), pp. 8-16.

Esparsa, C. "La interpretación tipográfica." Actas de diseño. Facultad de diseño y comunicación, Facultad de Palermo.

Espejo, A. (1975). Lenguaje, pensamiento y realidad. México: Editorial Edicol.

Frutinger, A. (1981). Signos símbolos marcas y señales. Barcelona: GG Diseño.

Galera, C. (2010). Perspectivas de la comunicación. Vol. 3, № 1. Universidad de la frontera. Temuco Chile.

Gamonal, R. (2005). Tipo-retórica, una aproximación a la retórica tipográfica. Revista icono, 14(5).

González, C. (1986). Imagen y sentido: Elementos para una semiótica de los mensajes visuales. México: UNAM.

Gray, B. (1989). Tips on type. London: Lund Humphries.

GRUPO $\mu$, (1993). Tratado del signo visual. Madrid: Cátedra.

Guiraud, P. (1972). La semiología. España: Siglo XXI Editores.

Harling, R. (1976). The letter forms and type designs of erick gill. Great Britain: Eva Svensson.

Heller, S. and Meggs, P. (2001). Texts on type critical writings on Typography. New York: Allworth Press.

Kalman, J. (2008). Discusiones conceptuales en el campo de la cultura escrita. Revista iberoamericana de educación, 46, pp. 107-134

Kloss, G. Algunas obviedades y herejías sobre legibilidad. Typo No 4, México

Korn, A. (1963). La historia construye la ciudad. Argentina: Editorial Universitaria de Buenos Aires.

Krampen, M. (1965). Signs and Symbols in Graphic Communication. Design Quarterly, 62, pp. 1-31.

Lewis, J. (1963). Typography: basic principles influences and trends since $19^{\text {th }}$ century. London: Studio Books.

Mandel, L. (1993). Developing an awareness of typographic letterforms. Electronic publishing, 6(1), pp. 322.

Marrone, C. (2007). Apariencia y realidad de la escritura. Revista escritura e imagen, 3, pp. 5-20.

Martínez, L. (1990). Treinta siglos de tipos y letras. México: UAM.

Marx, C. y Hobsbawn, E. J. (1971). Formaciones económicas precapitalistas, Pasado y Presente. México: Siglo XXI Editores.

Massin, J. (1970). Letter and image. London: Studio Vista. 
McLean, R. (2000). How typography Happens. London: The British Library.

Mifflin, H. (2000). The american heritage dictionary of english language. USA: Houghton Mifflin Company.

Moorhouse, A. (2006). Historia del alfabeto. México: Fondo de cultura económica.

Mosterín, J. (1993). Teoría de la escritura. España: Icaria Editorial.

Nazarenko, T. (2003). Re-Thinking the Value of the Linguistic and Non-Linguistic Sign: Russian Visual Poetry without Verbal Components. The Slavic and East European Journal, 47(3) (Autumn, 2003), pp. 393-422

Noordzij, G. (2000). Letterletter. Canada: Hartley and Marks.

Ockerse, T. Semiotics: principles in action for the graphic designer. http://mkgraphic.com/semiothics.html $22 / 08 / 2006$

Osnaya, S. (2011). Lettergraphy. The silent language. USA: lulu Press

- (2019). Significado, función y uso de los signos viales. Convergencias del diseño y de la construcción VI, México, Universidad autónoma de Aguascalientes

Ouaknin, M. (1999). Mysteries of the alphabet. New York: Abbeville Press.

Pérez, S. Escribir y argumentar. La innovación técnica del alfabeto. http://biblioteca.itam.mx 11/09/2010

- (2005). Escribas. México, UAM.

- (2006). La travesía de la escritura. México: Santillana editores.

Petrucci, A. (2003). La ciencia de la escritura. Argentina: Fondo de Cultura Económica.

Pirenne, H. (1942). Historia de Europa. Reid, M. and Turner, N., Legible/Visible. Yale French Studies, 84, Boundaries: Writing \& Drawing (1994), pp. 1-12

Riesco, A. (2002). Función social de la escritura. Revista General de Información y Documentación, 12(2), pp. 393-428.

Saussure, F. (1964). Nature of the linguistic sign. London: Peter Owen.

- (2000). Curso de lingüística general. Madrid: Ediciones Akal.

Schnewly, B. (1992). La concepción vygotskiana del lenguaje escrito. CL\&E, 16, pp. 49-59.

Serrano, S. (1983). Signos, lengua y cultura. Barcelona: Anagrama.

Thompson, P. and Daventport, P. (1980). The dictionary of visual language. London: Bergstrom and Boyle Books Limited.

Todorov, T. (1981). Teorías del símbolo. Venezuela: Monte Avila Editores.

Triggs, T. (2002). Back to basics. Graphics International, 98, pp. 18-19.

Varga A. (1989). Criteria for Describing Word-and-Image Relations. Poetics Today, 10(1), pp. 31-53.

Vegh, I. (2006). Las letras del análisis. Buenos Aires: Paidós.

Velilla, R. (1974). Saussure y Chomsky. Introducción a la lingüística. Colombia: Editorial Cincel.

Verlomme, M. (2005). Technological shifts in type design and production. Reading University.

Wallerstein, I. (1988). El capitalismo histórico. México: Siglo XXI Editores.

Wolf, L. y Massin, R. (2002). Massin in continuo: a dictionary interview with Robert Massin. Design Issues, 18(4), pp. 31-45.

Woolman, M. (1997). A type detective story. Switzerland: Roto Vision.

Yuen Ren Chao. (1970). Language and Symbolic Sistems. Cambridge: University Press. 